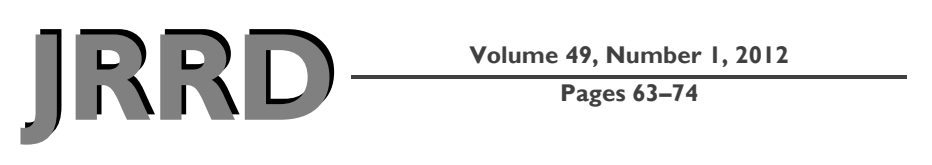

\title{
Assessment of field rolling resistance of manual wheelchairs
}

\author{
Christophe Sauret, PhD $;{ }^{\text {* }}$ Joseph Bascou, MS $;^{1-2}$ Nicolas de Saint Rémy, PhD; ${ }^{1}$ Hélène Pillet, PhD; ${ }^{1}$ Philippe \\ Vaslin, PhD; ${ }^{3-4}$ François Lavaste, PhD $^{1-2}$ \\ ${ }^{1}$ Arts et Métiers ParisTech, Laboratoire de Biomécanique, Paris, France; ${ }^{2}$ Institution Nationale des Invalides, Centre \\ d'Etudes et de Recherche sur l'Appareillage des Handicapés, Woippy, France; ${ }^{3}$ Clermont Université, Université Blaise \\ Pascal, Laboratoire d'Informatique, de Modélisation et d'Optimisation des Systèmes, Clermont-Ferrand, France; \\ ${ }^{4}$ Centre National de la Recherche Scientifique, Unité mixte de recherche, Laboratoire d'Informatique, de Modélisation \\ et d'Optimisation des Systèmes, Aubière, France
}

\begin{abstract}
This article proposes a simple and convenient method for assessing the subject-specific rolling resistance acting on a manual wheelchair, which could be used during the provision of clinical service. This method, based on a simple mathematical equation, is sensitive to both the total mass and its fore-aft distribution, which changes with the subject, wheelchair properties, and adjustments. The rolling resistance properties of three types of front casters and four types of rear wheels were determined for two indoor surfaces commonly encountered by wheelchair users (a hard smooth surface and carpet) from measurements of a three-dimensional accelerometer during field deceleration tests performed with artificial load. The average results provided by these experiments were then used as input data to assess the rolling resistance from the mathematical equation with an acceptable accuracy on hard smooth and carpet surfaces (standard errors of the estimates were 4.4 and $3.9 \mathrm{~N}$, respectively). Thus, this method can be confidently used by clinicians to help users make trade-offs between front and rear wheel types and sizes when choosing and adjusting their manual wheelchair.
\end{abstract}

Key words: carpet, caster, indoor floor, pneumatic tire, rehabilitation, roller, rolling resistance, soft roll, solid tire, wheel, wheelchair.

\section{INTRODUCTION}

Evaluating resistances is critical to the study of manual wheelchair (MWC) propulsion. In fact, the impact of resistance on the mechanical efficiency of MWC propulsion induces a decrease in the user's mobility, with potential risks including musculoskeletal disorders (i.e., pain and/or injuries). This has caused clinicians, scientists, and mechanical engineers to focus on this topic with the goal of minimizing such resistances. During propulsion, most of the energy supplied by the user is dissipated by rolling, turning, slipping, bearing, and air resistances. Because bearing resistance and air drag have been proven to be negligible in daily locomotion [1], the rolling, turning, and slipping resistances remain as causes of energy loss. However, no turning resistance occurs in straightforward propulsion. Therefore, under the assumption that the MWC does not slip, the present study focused on rolling resistance, which is mainly caused by inelastic deformations of the tires and ground [2].

Examining previous studies clarified the influences of tire type (pneumatic vs solid), pressure, rear wheel camber, and floor hardness on rolling resistance [3-8].

\footnotetext{
Abbreviations: $\mathrm{COM}=$ center of mass, $\mathrm{MWC}=$ manual wheelchair, $\mathrm{RF}=$ rolling resistance factor, $\mathrm{RP}=$ rolling resistance parameter, SEE = standard error of the estimate.

*Address all correspondence to Christophe Sauret, PhD; Laboratoire de Biomécanique - Arts et Métiers ParisTech, 151 boulevard de l'Hôpital, Paris 75013, France; +33144246364; fax: +330144246366. Email: christophe.sauret@ensam.eu http://dx.doi.org/10.1682/JRRD.2011.03.0050
} 
Furthermore, MWC propulsion models [1,9-13] have established the relation between wheel radius and rolling resistance; i.e., for a given laden weight, the wheel rolling resistance increases when the radius is reduced and vice versa. This relation thus explains the increase in MWC rolling resistance when the mass is brought forward [4,11-15]. Rear wheel toe-in/-out could also be an important source of resistance [3], but this mechanical phenomenon may not be considered part of rolling resistance because it is a consequence of the rear wheels' slipping (the wheel trajectories are not perfectly in their rotational plans, inducing a slipping friction of the wheels on the floor) and can be cancelled by appropriate rear wheel alignment. All the findings of the different studies conducted on MWC rolling resistance provide useful guidelines for clinicians and users when choosing and adjusting a MWC. However, these recommendations are not listed in terms of importance and may not all be satisfied at one time. Thus, compromises are usually made by clinicians when optimizing a MWC, with no quantified visibility for the benefits. Hence, a simple and fast tool to assess the rolling resistance in clinical practice is needed.

In order to quantify rolling resistance acting on a MWC, different experimental methods have been developed in the past. The first one measured the drag force (with a force transducer) occurring on a treadmill [2$3,5,16]$. The main problem with this method was that rolling resistance depended on the material of the treadmill belt and did not allow evaluation of different surfaces. Other authors quantified the rolling resistance from deceleration tests (or coast-down tests) performed in the field by measuring the MWC deceleration with a subject sitting in the MWC [17-20]. These methods allowed evaluation of various surfaces but neglected the influence of the fore-aft distribution of the total mass, which conduces to major changes in rolling resistance. Hence, experiments were required to test the influence on rolling resistance of each adjustment of the MWC and each choice of wheels. Finally, a method also based on deceleration tests performed in the field with artificial masses and with various fore-aft distribution of the total mass was developed [11-13,21-22]. In this case, the rolling resistance offered by a MWC was calculated from coefficients linked to the loads applied on front and rear wheels. This method allows quantification of the rolling resistance of a MWC on various surfaces and simulates the effect of various adjustments, which change the foreaft distribution of the mass. However, all these methods are time consuming during MWC adjustment. Therefore, they are not applicable in clinical routine.

In this context, the aim of this study was to develop a simple method for assessing subject-specific MWC rolling resistance in clinical practice.

\section{METHODS}

\section{Model of Rolling Resistance}

In order to quantify MWC rolling resistance, deceleration tests were performed on a horizontal surface [14 15,17-22]. During these tests, the MWC was first pushed forward (push phase) manually, released, and allowed to decelerate (deceleration phase). This deceleration was caused only by the rolling resistance, assuming that the MWC did not deviate and neglecting the bearing, slipping, and air resistances [1,4]. The mechanical model (detailed in Appendix 1, available online only) of the deceleration phase, linking the deceleration both to the forces and torques exerted on the MWC, was as follows:

$$
\gamma_{G}=-m g \frac{\left(\frac{\lambda_{f}}{r_{f}} \frac{d_{r}}{w_{b}}+\frac{\lambda_{r}}{r_{r}} \frac{d_{f}}{w_{b}}+\frac{\lambda_{f} \lambda_{r}}{r_{f} r_{r}} \frac{r_{f}-r_{r}}{w_{b}}\right)}{\left(m+\frac{I_{f}}{r_{f}^{2}}+\frac{I_{r}}{r_{r}^{2}}\right)\left(1+\frac{\lambda_{f}-\lambda_{r}}{w_{b}}\right)+\left(m+\frac{I_{f}}{r_{f} h}+\frac{I_{r}}{r_{r} h}\right)\left(\frac{\lambda_{r}}{r_{r}}-\frac{\lambda_{f}}{r_{f}}\right) \frac{h}{w_{b}}},
$$

where $\gamma_{G}$ is the linear deceleration along the fore-aft direction (in meters per second squared); $g$ is the gravitational acceleration (in meters per second squared); $\lambda_{f}$ and $\lambda_{r}$ are the front and rear wheel rolling resistance parameters (RPs) (in meters), respectively, characterizing the rolling resistance property caused by the contact between the wheels and floor and modeled as the fore-aft length between the theoretical and real centers of pressure in the contact area (Figure 1); $r_{f}$ and $r_{r}$ are the front and rear wheel radii (in meters); $d_{f}$ and $d_{r}$ are the fore-aft distances between the global center of mass (COM) and the front and rear wheel hubs (in meters), respectively; $w_{b}$ is the wheelbase (in meters), defined as the fore-aft distance between the front and rear hubs; $m$ is the total mass (in kilograms); $h$ is the height to the ground of the global COM (in meters); and $I_{f}$ and $I_{r}$ are the moments of inertia of the two front and the two rear wheels around their rotational axes (in kilogram-meters squared), respectively.

This equation was used as an exhaustive model for the MWC rolling resistance during the deceleration phase of the test. However, it could be simplified by leaving out 


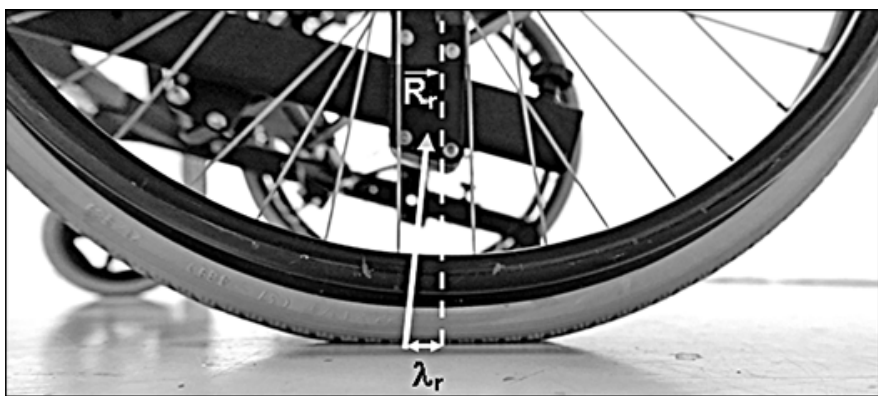

Figure 1.

Representation of rear wheel rolling resistance parameter, which is fore-aft length between theoretical and real centers of pressure during rolling. $\overrightarrow{R_{r}}$ is ground reaction force applied on rear wheel.

some terms with an error that was lower than 5 percent (see details in Appendix 2, available online only):

$$
\gamma_{G}=-g\left(\frac{\lambda_{f}}{r_{f}} \frac{d_{r}}{w_{b}}+\frac{\lambda_{r}}{r_{r}} \frac{d_{f}}{w_{b}}\right) .
$$

Moreover, when replacing $w_{b}, d_{f}$, and $d_{r}$ with the masses applied to the front and rear wheels $\left(m_{f}\right.$ and $m_{r}$, respectively) and the total mass $(\mathrm{m})$, the model is close to those previously proposed [1,9].

$$
\gamma_{G}=-g\left(\frac{\lambda_{f}}{r_{f}} \frac{m_{f}}{m}+\frac{\lambda_{r}}{r_{r}} \frac{m_{r}}{m}\right) .
$$

This equation shows that the MWC deceleration is inversely related to the wheel radii. Because the front casters have smaller radii than the rear wheels, the MWC deceleration would be more influenced by the mass distribution on the front wheels than the rear wheels [1114]. Finally, the rolling resistance can also be expressed by means of a resisting force $\left(F_{\text {roll }}\right)$ sustained by the subject during propulsion:

$$
F_{\text {roll }}=m \gamma_{G} \Leftrightarrow m \gamma_{G}=-g\left(\frac{\lambda_{f}}{r_{f}} m_{f}+\frac{\lambda_{r}}{r_{r}} m_{r}\right) \text {. }
$$

The RP characterizes the resistance acting at the contact level between the wheels and ground and greatly depends on the materials used for both. The rolling resistance factor (RF) is the ratio between RP and the wheel radius; it characterizes the wheel's specific rolling quality based on its size and the type of floor. Therefore, RF increases with an increase in RP or a decrease in wheel radius. The resisting force $\left(F_{\text {roll }}\right)$ characterizes the inten- sity of the MWC rolling resistance for a given subject during propulsion on a specific floor.

\section{Experiments}

Two approaches could be used to characterize the rolling resistance properties ( $\mathrm{RP}$ and $\mathrm{RF}$ ) for different types of front and rear wheels. The first one uses a single chair and replaces the wheels, while the other uses several chairs already equipped with various wheels. If the same chair were to be used, then resistances such as the air drag and frame deformations would remain unchanged. However, all the wheels cannot be mounted on the same chair because of differences in the rear wheel axles and fork geometries, inducing the need for several chairs. Thus, we selected the second approach, while neglecting the air drag and frame deformation effects $[1,4]$.

Thirty-three different MWCs (Table 1) were tested on two typical indoor surfaces: a hard smooth surface (polished concrete type) and carpet (loop pile carpet [5.4 mm] laid on concrete). For pneumatic rear wheels, the pressures were respectively set to their advised maximum values, which ranged from 43.5 to 87.0 psi. Rehabilitation experts performed the wheel alignments to minimize the toe-in/-out effect. A there-and-back procedure was undertaken to override possible flatness imperfections in the floor [16-17,20]. The deceleration was measured by use of a wireless three-dimensional accelerometer (sensitivity: \pm 2 g; Beanscape AX-3D; Neuvillesur-Oise, France) with a sampling frequency of $100 \mathrm{~Hz}$ [21-23] that was fixed to the loads placed on the seat.

For each MWC, 4 sets of 20 deceleration tests $(80$ tests total) were performed on each surface and the mean deceleration of every set was computed. The number of deceleration tests for each set was defined to give both acceptable accuracy and a feasible protocol in terms of experiment time (around 1 hour for one MWC on the two tested surfaces). For each set, the mass distribution on the front and rear wheels was changed by alternatively placing the loads forward or backward (Table 1) and was measured with use of a specific weight-scale platform (resolution: $0.05 \mathrm{~kg}$ ). In summary, 5,280 deceleration tests were performed $(20$ tests $\times 4$ sets $\times 33$ MWCs $\times$ 2 floors). The initial velocities at the beginning of the deceleration phase, computing from the acceleration signals, ranged from 1.5 to $2.5 \mathrm{~m} / \mathrm{s}$.

A system, comprising Equation 3 written four times and applied to the four sets, was thus available for each MWC for every surface and only included two unknown 
JRRD, Volume 49, Number 1, 2012

Table 1.

Manual wheelchair properties and load settings used for experiments.

\begin{tabular}{|c|c|c|c|c|c|c|c|c|}
\hline \multirow{2}{*}{$\begin{array}{l}\text { Company } \\
\text { (Model) }\end{array}$} & \multicolumn{3}{|c|}{ Front Casters } & \multicolumn{3}{|c|}{ Rear Wheels } & \multicolumn{2}{|c|}{ Load Setting [set 1 , set 2 , set 3 , set 4$]$} \\
\hline & Type & Radius (m) & $\begin{array}{l}\text { Psi vs } \\
\text { Solid }\end{array}$ & Width (in.) & $\begin{array}{c}\text { Tread } \\
\text { Design }\end{array}$ & Radius (m) & Total Mass (kg) & $\begin{array}{c}\text { Front Distribution } \\
(\%)\end{array}$ \\
\hline $\begin{array}{l}\text { Dietz GMBH } \\
\text { (Pro Activ Traveler) }\end{array}$ & Standard & 0.064 & 87.0 & $1-3 / 8$ & Street & 0.312 & {$[67,64,103,103]$} & {$[10,57,8,60]$} \\
\hline $\begin{array}{l}\text { Invacare } \\
\text { (Kuschall Champ Carb) }\end{array}$ & Soft & 0.063 & 87.0 & 1 & Smooth & 0.299 & {$[75,75,99,90]$} & {$[29,63,22,69]$} \\
\hline $\begin{array}{l}\text { Sunrise Medical } \\
\text { (Quickie Easy Max) }\end{array}$ & Soft & 0.071 & 87.0 & 1 & Smooth & 0.298 & {$[67,68,106,107]$} & {$[9,68,10,58]$} \\
\hline $\begin{array}{l}\text { Sunrise Medical } \\
\text { (Quickie Matchpoint) }\end{array}$ & Roller & 0.040 & 87.0 & 1 & Smooth & 0.297 & {$[83,83,106,106]$} & {$[6,24,12,24]$} \\
\hline $\begin{array}{l}\text { Otto Bock } \\
\text { (Avant-Garde T) }\end{array}$ & Soft & 0.072 & 87.0 & 1 & Street & 0.299 & {$[68,68,107,107]$} & {$[12,83,12,65]$} \\
\hline $\begin{array}{l}\text { Livestand } \\
\text { (LSA Helium) }\end{array}$ & Standard & 0.059 & 87.0 & 1 & Street & 0.299 & {$[83,83,102,107]$} & {$[17,51,17,56]$} \\
\hline $\begin{array}{l}\text { Sunrise Medical } \\
\text { (Quickie 2HP) }\end{array}$ & Standard & 0.061 & 87.0 & $1-3 / 8$ & Street & 0.307 & {$[69,69,117,117]$} & {$[46,78,29,85]$} \\
\hline $\begin{array}{l}\text { Sunrise Medical } \\
\text { (Classic } 160 \text { Recline) }\end{array}$ & Soft & 0.070 & Solid & $1-3 / 8$ & Smooth & 0.306 & {$[83,84,115,115]$} & {$[39,50,44,55]$} \\
\hline $\begin{array}{l}\text { Progeo } \\
\text { (Exelle Vario) }\end{array}$ & Soft & 0.060 & 87.0 & 1 & Smooth & 0.297 & {$[80,83,103,108]$} & {$[14,39,17,42]$} \\
\hline $\begin{array}{l}\text { Rehateam } \\
\text { (Projeo Jocker) }\end{array}$ & Soft & 0.062 & 87.0 & 1 & Smooth & 0.297 & {$[66,67,106,103]$} & {$[6,77,7,53]$} \\
\hline $\begin{array}{l}\text { Dupond Medical } \\
\text { (Optimo Confort) }\end{array}$ & Standard & 0.097 & Solid & $1-3 / 8$ & Street & 0.302 & {$[92,93,131,132]$} & {$[13,79,11,77]$} \\
\hline $\begin{array}{l}\text { Invacare } \\
\text { (Rea Azalea) }\end{array}$ & Standard & 0.099 & 87.0 & $1-3 / 8$ & Smooth & 0.306 & {$[102,102,125,125]$} & {$[41,68,44,66]$} \\
\hline $\begin{array}{l}\text { Otto Bock } \\
\text { (Innov XXL) }\end{array}$ & Standard & 0.074 & 87.0 & $1-3 / 8$ & Street & 0.310 & {$[100,100,141,141]$} & {$[27,52,26,54]$} \\
\hline $\begin{array}{l}\text { Invacare } \\
\text { (Action } 3 \text { Junior) }\end{array}$ & Standard & 0.063 & Solid & $1-3 / 8$ & Smooth & 0.279 & {$[56,62,84,82]$} & {$[26,46,29,49]$} \\
\hline $\begin{array}{l}\text { Meyra } \\
\text { (Offense 1.879) }\end{array}$ & Roller & 0.040 & 87.0 & 1 & Smooth & 0.292 & {$[75,75,97,102]$} & {$[14,32,16,26]$} \\
\hline $\begin{array}{l}\text { Invacare } \\
\text { (Action } 4 \text { XLT) }\end{array}$ & Soft & 0.096 & 65.0 & $1-3 / 8$ & Street & 0.313 & {$[73,80,112,113]$} & {$[29,83,23,74]$} \\
\hline $\begin{array}{l}\text { Meyra } \\
(\text { X2 3.351) }\end{array}$ & Standard & 0.063 & 65.0 & $1-3 / 8$ & Street & 0.308 & {$[79,84,102,103]$} & {$[15,45,14,54]$} \\
\hline $\begin{array}{l}\text { Dupond Medical } \\
\text { (Alto Plus F) }\end{array}$ & Standard & 0.097 & 87.0 & 1 & Smooth & 0.293 & {$[71,72,110,11]$} & {$[25,83,24,72]$} \\
\hline $\begin{array}{l}\text { Dupond Medical } \\
\text { (Primeo C) }\end{array}$ & Standard & 0.095 & 43.5 & $1-3 / 8$ & Street & 0.305 & {$[84,92,112,112]$} & {$[32,58,31,62]$} \\
\hline $\begin{array}{l}\text { Meyra } \\
\text { (FX One) }\end{array}$ & Soft & 0.074 & 87.0 & 1 & Smooth & 0.299 & {$[76,79,108,111]$} & {$[12,34,17,49]$} \\
\hline $\begin{array}{l}\text { RGK } \\
\text { (Interceptor) }\end{array}$ & Roller & 0.036 & 87.0 & 1 & Smooth & 0.295 & {$[64,65,103,103]$} & {$[7,69,5,53]$} \\
\hline $\begin{array}{l}\text { Invacare } \\
\text { (Top End Transformer) }\end{array}$ & Roller & 0.040 & 87.0 & 1 & Smooth & 0.298 & {$[74,74,106,103]$} & {$[12,24,17,32]$} \\
\hline $\begin{array}{l}\text { Bischoff \& Bischoff } \\
\text { (Triton) }\end{array}$ & Standard & 0.086 & Solid & $1-3 / 8$ & Smooth & 0.300 & {$[107,107,133,133]$} & {$[38,62,42,54]$} \\
\hline $\begin{array}{l}\text { Dietz GMBH } \\
\text { (Primo Amico) }\end{array}$ & Standard & 0.090 & 65.0 & $1-3 / 8$ & Street & 0.309 & {$[84,90,107,111]$} & {$[24,62,24,62]$} \\
\hline $\begin{array}{l}\text { Invacare } \\
\text { (Rea Clematis) }\end{array}$ & Standard & 0.097 & 43.5 & $1-3 / 8$ & Street & 0.305 & {$[89,90,127,128]$} & {$[15,83,20,73]$} \\
\hline $\begin{array}{l}\text { Invacare } \\
\text { (Action } 3 \text { Positioning) }\end{array}$ & Standard & 0.074 & 65.0 & $1-3 / 8$ & Street & 0.304 & {$[75,79,116,117]$} & {$[15,68,8,66]$} \\
\hline $\begin{array}{l}\text { Invacare } \\
\text { (Kushall AG) }\end{array}$ & Standard & 0.051 & 87.0 & 1 & Street & 0.299 & {$[70,71,97,98]$} & {$[9,84,8,82]$} \\
\hline
\end{tabular}


Table 1. (cont)

Manual wheelchair properties and load settings used for experiments.

\begin{tabular}{|c|c|c|c|c|c|c|c|c|}
\hline \multirow[b]{2}{*}{$\begin{array}{l}\text { Company } \\
\text { (Model) }\end{array}$} & \multicolumn{3}{|c|}{ Front Casters } & \multicolumn{3}{|c|}{ Rear Wheels } & \multicolumn{2}{|c|}{ Load Setting [set 1, set 2, set 3, set 4] } \\
\hline & Type & Radius (m) & $\begin{array}{l}\text { Psi vs } \\
\text { Solid }\end{array}$ & Width (in.) & $\begin{array}{c}\text { Tread } \\
\text { Design }\end{array}$ & Radius (m) & Total Mass (kg) & $\begin{array}{c}\text { Front Distribution } \\
(\%)\end{array}$ \\
\hline $\begin{array}{l}\text { RGK } \\
\text { (Hi Lite) }\end{array}$ & Roller & 0.051 & 87.0 & 1 & Smooth & 0.297 & {$[81,81,99,99]$} & {$[22,51,24,51]$} \\
\hline $\begin{array}{l}\text { Rupiani } \\
\text { (Fuze T20 PDG) }\end{array}$ & Standard & 0.072 & 65.0 & $1-3 / 8$ & Street & 0.307 & {$[99,99,121,121]$} & {$[32,57,32,72]$} \\
\hline $\begin{array}{l}\text { Invacare } \\
\text { (Top end Pro Tennis) }\end{array}$ & Roller & 0.036 & 87.0 & 1 & Smooth & 0.298 & {$[78,78,101,101]$} & {$[3,23,2,22]$} \\
\hline $\begin{array}{l}\text { Vermeiren } \\
\text { (795 TII) }\end{array}$ & Standard & 0.101 & Solid & $1-3 / 8$ & Smooth & 0.282 & {$[110,116,148,159]$} & {$[29,45,40,49]$} \\
\hline $\begin{array}{l}\text { Vermeiren } \\
\text { (R708 TII) }\end{array}$ & Standard & 0.101 & 43.5 & $1-3 / 8$ & Street & 0.306 & {$[69,71,108,110]$} & {$[20,80,22,74]$} \\
\hline
\end{tabular}

variables: the RP values for the front $\left(\lambda_{f}\right)$ and rear $\left(\lambda_{r}\right)$ wheels. Each system was then written in a matrix form:

$$
\underbrace{\left[\begin{array}{c}
\gamma_{G(s e t 1)} \\
\gamma_{G(s e t 2)} \\
\cdots
\end{array}\right]}_{\left[M_{A}\right](4 \times 1)}=-g \cdot \underbrace{\left[\begin{array}{cc}
\frac{1}{r_{f}} \frac{m_{f}(\text { set } 1)}{m_{(s e t 1)}} & \frac{1}{r_{r}} \frac{m_{r}(\text { set } 1)}{m_{(s e t 1)}}
\end{array}\right]}_{\left[M_{D}\right](4 \times 2)} \cdot \underbrace{\left[\begin{array}{c}
\lambda_{f} \\
\lambda_{r}
\end{array}\right]}_{\left[M_{R P}\right](2 \times 1)},
$$

in which $\left[\mathrm{M}_{A}\right]$ is the acceleration matrix containing the measured decelerations, $\left[\mathrm{M}_{D}\right]$ is the distribution matrix containing the wheels' radii and mass distributions, and $\left[\mathrm{M}_{R P}\right]$ contained the unknown RPs. The latter were then computed as follows:

$$
\left[\mathrm{M}_{R P}\right]=\left[-g\left[\mathrm{M}_{D}\right]^{T}\left[\mathrm{M}_{D}\right]\right]^{-1}\left[\mathrm{M}_{D}\right]^{T}\left[\mathrm{M}_{A}\right] \text {. }
$$

For the 33 MWCs, the system was respectively solved for each surface.

\section{Data Analysis}

The RPs $\left(\lambda_{f}\right.$ and $\left.\lambda_{r}\right)$ for each MWC (on the two tested surfaces) were analyzed based on the types of front and rear wheels. A rehabilitation specialist sorted the front casters into three groups (Table 2): soft roll, standard, and roller casters. The rear wheels were gathered into four groups: three for pneumatic tires according to their inflating pressure (43.5, 65.0, and $87.0 \mathrm{psi}$ ) and one for solid tires.

A statistical analysis was carried out to ascertain whether significant RP differences existed between the various wheels and floor types. Because of the small sizes of the groups (ranging between 3 and 20), nonparametric tests were used (Kruskal-Wallis or Mann-Whitney to compare the wheel types and Wilcoxon signed-rank for floor types). All the comparisons were two-sided and $p$-values $\leq$ 0.05 were considered significant.

To validate the predicting model for the MWC rolling resistance per surface, we used a leave-one-out cross validation technique and evaluated the accuracy by means of the standard error of the estimate (SEE).

\section{RESULTS}

\section{Manual Wheelchair Deceleration}

The decelerations ranged from -0.02 to $-0.34 \mathrm{~m} / \mathrm{s}^{2}$ on a hard smooth surface and from -0.12 to $-0.59 \mathrm{~m} / \mathrm{s}^{2}$ on carpet. For both surfaces, the decelerations increased when the mass distribution on the front casters was augmented

Table 2.

Properties (mean \pm standard deviation) of three types of front casters and four types of rear wheels.

\begin{tabular}{lrl}
\hline \multicolumn{1}{c}{ Type } & No. & Radius (m) \\
\hline FW & 8 & $0.071 \pm 0.011$ \\
Soft Casters & 19 & $0.079 \pm 0.019$ \\
Standard Casters & 6 & $0.040 \pm 0.005$ \\
Roller Casters & & \\
RW & 5 & $0.296 \pm 0.016$ \\
Solid Tires & 3 & $0.306 \pm 0.009$ \\
Pneumatic Tires 43.5 psi & 5 & $0.308 \pm 0.003$ \\
Pneumatic Tires 65.0 psi & 20 & $0.300 \pm 0.005$ \\
Pneumatic Tires 87.0 psi & & \\
FW= front wheels, RW = rear wheels. &
\end{tabular}


(Figure 2). In addition, this increase was more important on carpet than on the hard smooth surface. The MWC rolling resistances $\left(F_{\text {roll }}\right)$ ranged from -2.9 to $-32.6 \mathrm{~N}$ on a hard smooth surface and from -11.2 to $-61.6 \mathrm{~N}$ on carpet.

\section{Wheel Rolling Properties (Rolling Resistance Param- eter and Rolling Resistance Factor)}

For each type of front caster, the RP value was significantly higher on carpet than on the hard smooth surface (Figure 3). The RP values of every type of rear wheel were also higher on carpet than the hard smooth surface, but the statistics could not be computed for all the groups because of the small sample sizes. The only significant difference was found for pneumatics inflated to $87.0 \mathrm{psi}$.

On both surfaces, the RP values were found to be significantly different according to the caster types ( $p<$ 0.001). Standard casters showed the highest RP, followed by soft and then roller casters. Therefore, for a given radius, standard casters had the biggest $\mathrm{RF}$, whereas roller casters had the smallest (Figure 4). Figure 4 shows that the same RF value could be obtained for all the caster types when setting different radii. For the same caster, Figure 4 shows that RF decreased when the radius was augmented. However, the effect on RF of a caster radius variation evolved with the enlargement of the radius: the smaller the radius, the higher the effect and vice versa.

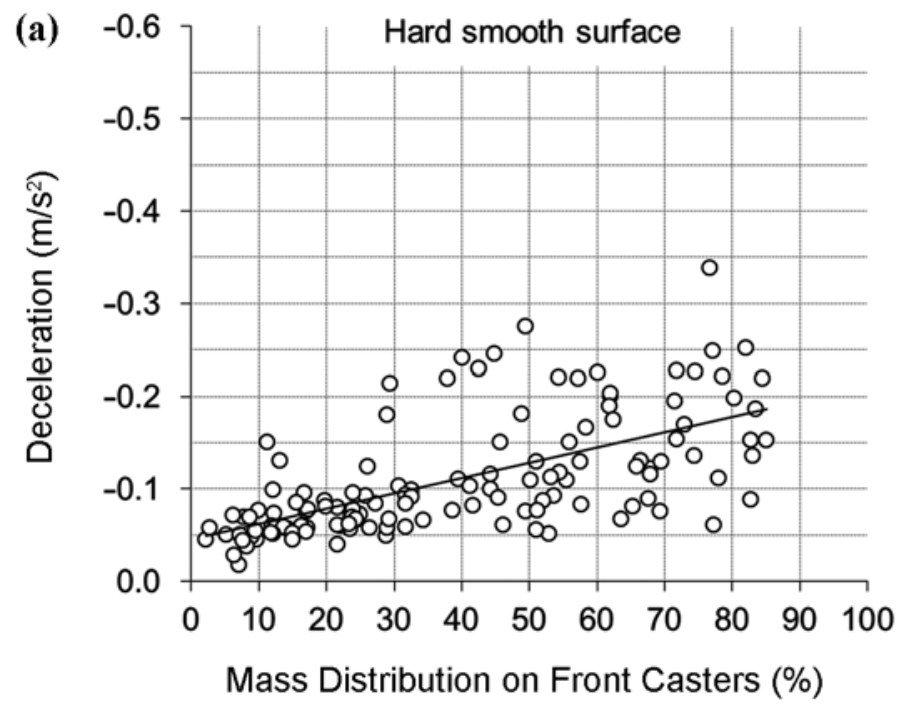

Surprisingly, the rear wheel pneumatics showed that tires inflated to 87.0 psi exhibited a higher RP than those inflated to 43.5 and 65.0 psi (Figure 3). However, the first group included six cambered wheels, which showed a slightly higher RP than the rest of the group on the hard smooth $(1.91 \pm 0.66 \mathrm{~mm}$ vs $1.10 \pm 0.56 \mathrm{~mm})$ and carpet surfaces $(4.81 \pm 0.90 \mathrm{~mm}$ vs $4.69 \pm 1.11 \mathrm{~mm})$. Nevertheless, the statistics did not reveal significant differences between the pneumatic types for either the hard smooth $(p=0.18)$ or carpet surface $(p=0.57)$. Then, all the pneumatic tires were gathered into the same group, which showed significantly lower RP values than the solid tires on both surfaces. Hence, the solid tires exhibited a higher $\mathrm{RF}$ than the pneumatic tires for any wheel radius (ranging from 0.25 to $0.35 \mathrm{~m}$ ) (Figure 5).

Finally, on the hard smooth surface, the pneumatic rear wheels showed a higher RP value than the roller $(p<$ $0.001)$, soft $(p=0.04)$, and standard casters $(p=0.002)$. On carpet, the RP of the pneumatic rear wheels was also higher than those of the roller $(p<0.001)$, soft $(p<0.001)$, and standard $(p<0.001)$ casters. In addition, the effect of the radius variation on RF appeared to be significantly smaller than that for front casters.

\section{Assessment of Manual Wheelchair Rolling Resistance}

The accuracy of the MWC rolling resistance assessments was evaluated with a leave-one-out crossvalidation

(b)

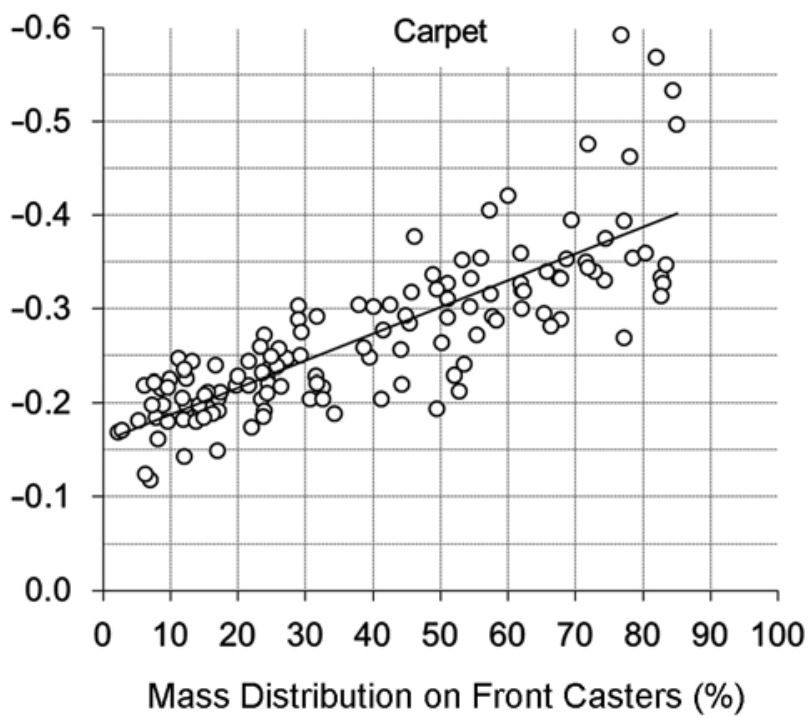

Figure 2.

Results of measured manual wheelchair decelerations during 132 sets performed on (a) hard smooth surface and (b) carpet and respective linear regressions (thin lines) with respect to percentage of total mass distributed on front casters. 


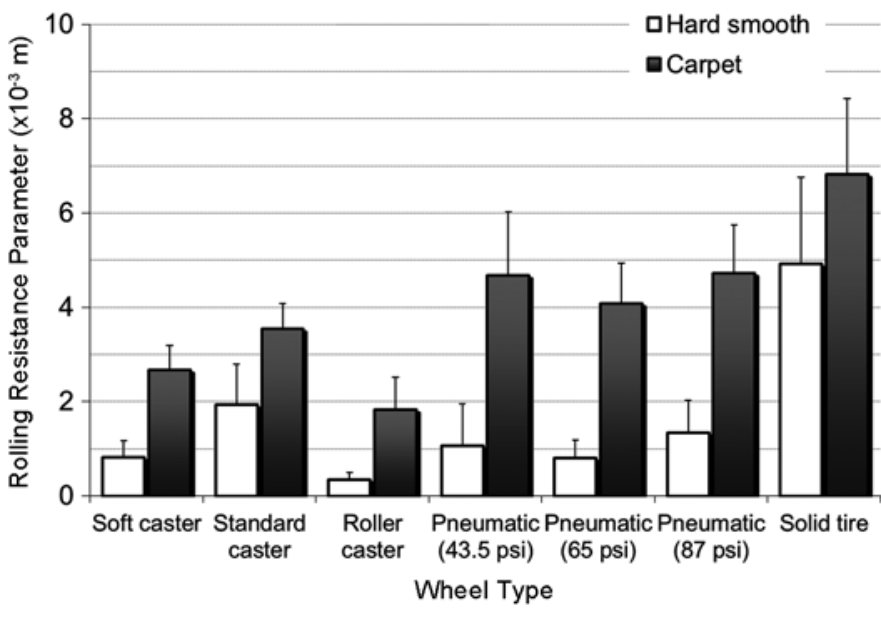

Figure 3.

Rolling resistance parameter values of front and rear wheels according to wheel types on hard smooth and carpet surfaces.

technique (Figure 6). The SEE values were 4.4 and $3.9 \mathrm{~N}$ on the hard smooth and carpet surfaces, respectively. Finally, the mean RP values computed from all the data are summarized in Table 3.

\section{DISCUSSION}

Modeling the MWC rolling resistance (Equation 4) provided helpful information for decreasing it based on the geometric properties of the MWC. For example, enlarging the wheel radii made decreasing the rolling resistance possible. The rolling resistance could also be decreased by adjusting the MWC with a change in the rear wheel foreaft position, which modified the masses applied to the front and rear wheels. For instance, when the front casters exhibited a higher RF than the rear wheels, the latter could be brought forward to decrease the load on the front casters and thus drop the MWC rolling resistance. When RP values for the front and rear wheels are previously known, the $R F$ values can be easily calculated by measuring the wheel radii. Hence, the measurements of the masses applied on front and rear wheels (using weight scale plate-forms) when the user is sitting in the MWC allow estimation (using Equation (4)) of the specific rolling resistance sustained with this MWC. In this case, the required measurements are very easy and fast to do and the method becomes applicable in clinical routine by clinicians or other members of the rehabilitation team.
Because MWC rolling resistance is related to the type of floor, the RP values were determined for two different surfaces: a hard smooth surface and carpet. For that purpose, deceleration tests were performed directly in the field. This experimental setting made it possible to test any surface, which cannot be done with drum-dynamometers $[6,8]$ or treadmills $[2,5,16]$. During the deceleration tests, the bearing resistance, air drag, and wheel toe-in/-out effect were neglected. However, so that these hypotheses could be assumed, the MWC velocity did not exceed $2.5 \mathrm{~m} / \mathrm{s}$, the ball-bearings were clean and not overused, and wheel alignments were carried out by rehabilitation experts.

In order to compute the RP values, we performed the deceleration tests with four load settings for each MWC on every surface. The results for these four conditions were then used to solve a system of four equations with only two unknowns. Even though two loads would have been enough, a system of four equations offered more reliable results. Therefore, the variations in RP with the load were neglected based on the good linearity previously found [24].

On the hard smooth surface, the decelerations were consistent with the previous ones obtained on a hardwood gymnasium surface [14-15,17]. On carpet, the decelerations were slightly higher than those obtained on short pile carpet [13] but in the same range as those obtained on an athletic track [11-12,15]. On both surfaces, the deceleration increased with the percentage of the total mass distributed on the front wheels as in the previous observations [4,11-15]. Furthermore, this result reveals that the rolling resistance of MWC could not be evaluated using a single load setting, as is often done $[20,25]$.

The MWC rolling resistances obtained on the hard smooth surface were consistent with the previous results, ranging from -2.9 to $-22.6 \mathrm{~N}$ [3,16-19]. On carpet, the rolling resistances were higher than on the hard smooth surface, which confirmed the conclusions of Koontz et al. [26]. These authors found that, for a given velocity, the propelling torque was higher on carpet than on linoleum or tiled floors. Therefore, they suggested that this resulted from higher rolling resistance. Frank and Abel earlier showed that the rolling resistances of casters on carpet were higher than on a vinyl surface [24]. However, they did not use a MWC but a trolley equipped with four casters. Finally, the 

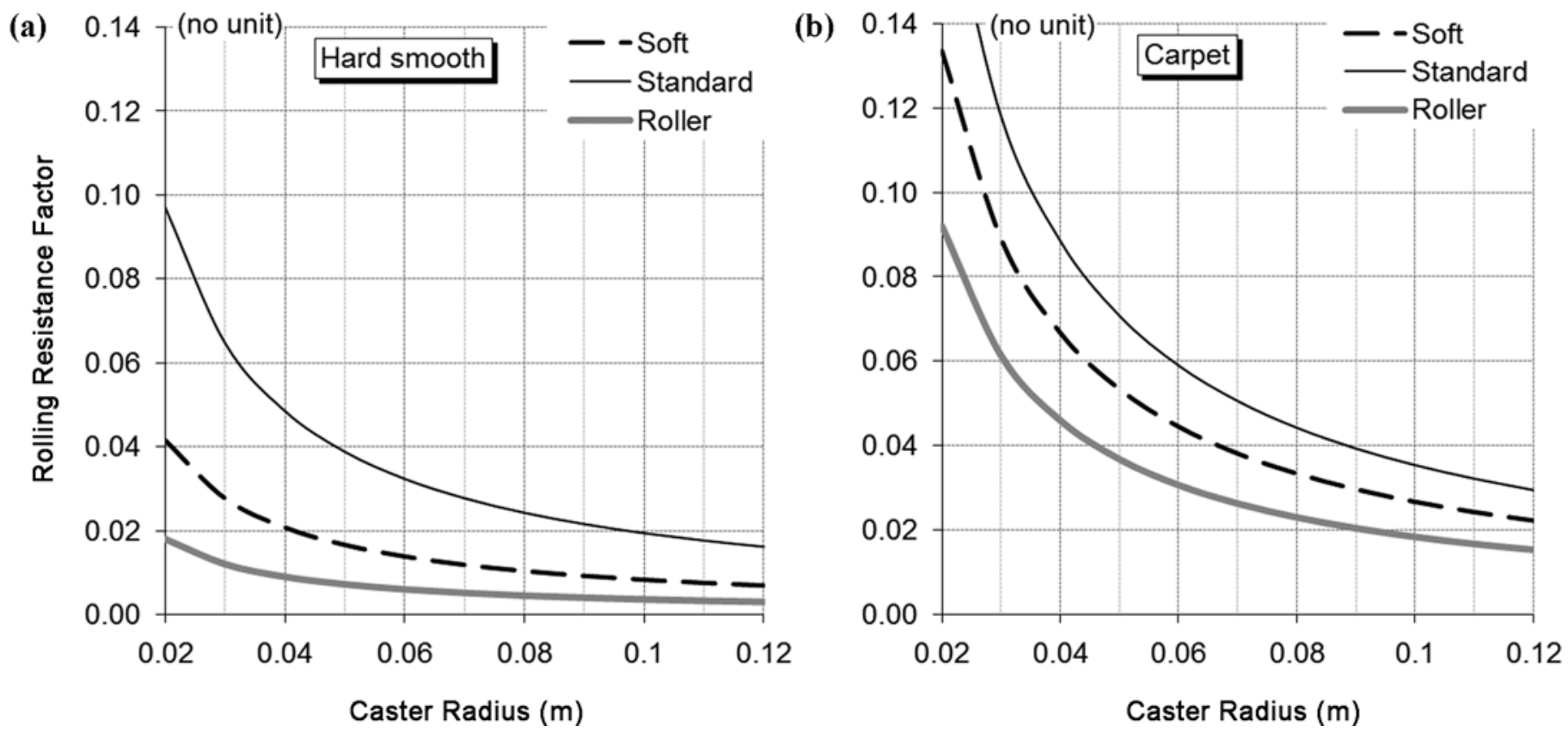

Figure 4.

Evolution of rolling resistance factor of soft (dashed line), standard (thin line), and roller (gray thick line) casters with respect to radius values on (a) hard smooth and (b) carpet surfaces.
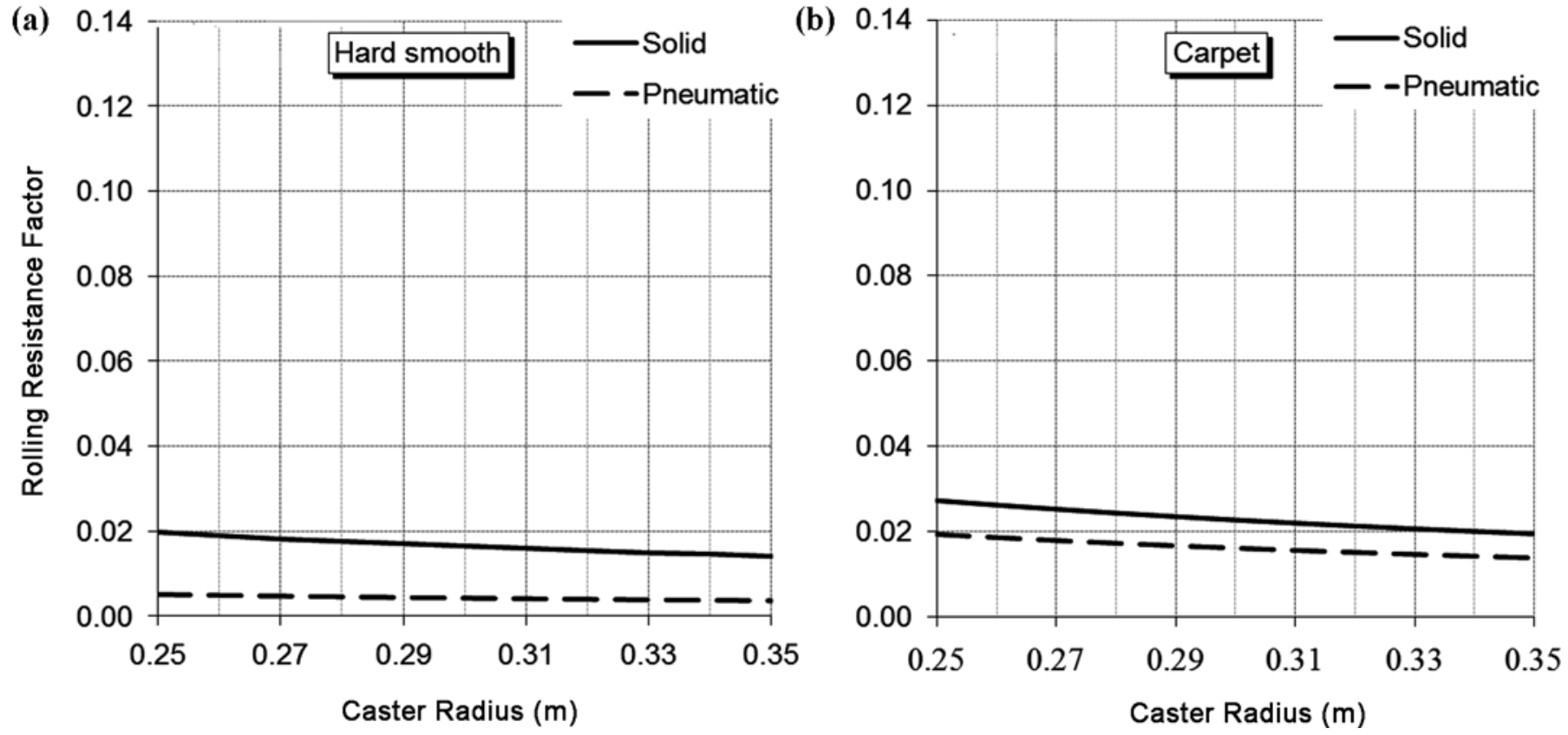

Figure 5.

Evolution of rolling resistance factor of rear wheels solid (solid line) and pneumatic (dashed line) tires with respect to radius values on (a) hard smooth and (b) carpet surfaces. 

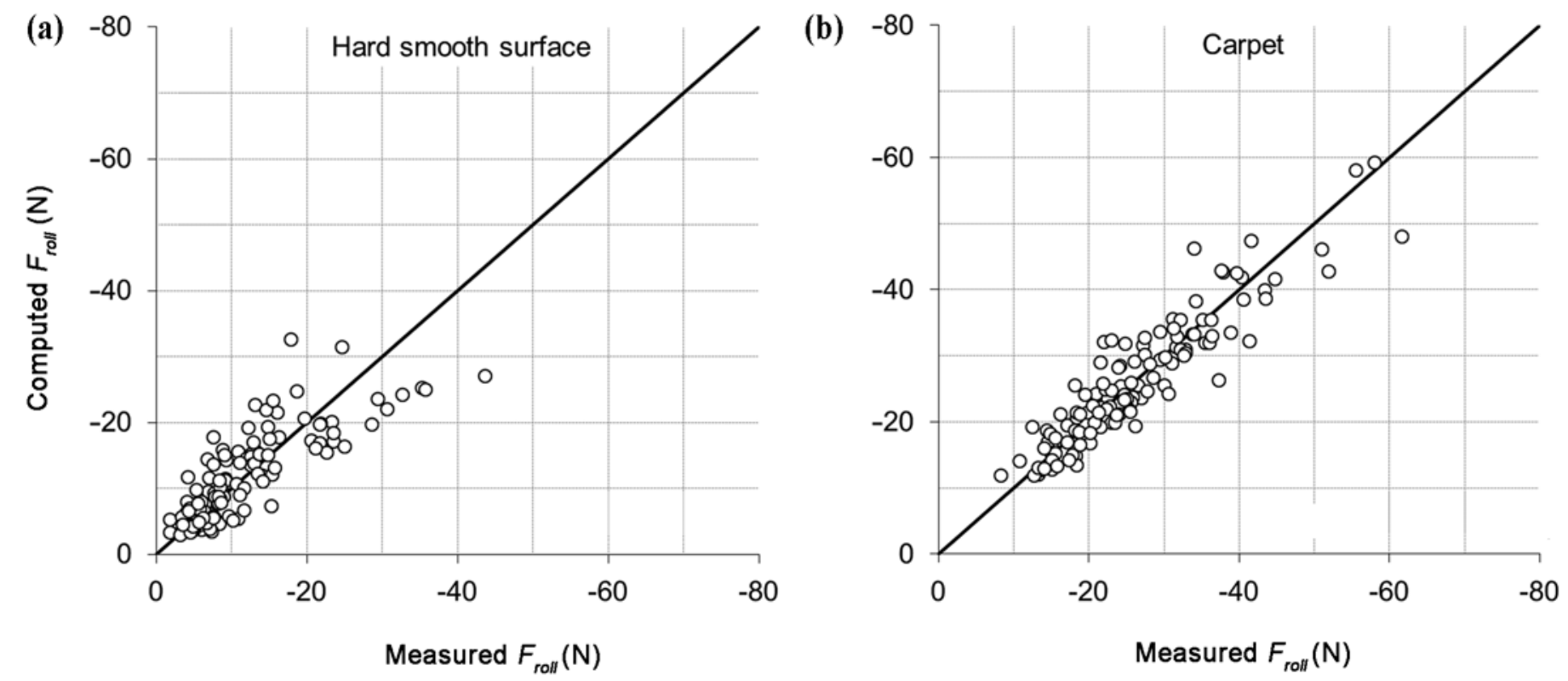

Figure 6.

Comparison of $F_{\text {roll }}$ calculated from measured decelerations (Measured $F_{\text {roll }}$ ) and those computed by leave-one-out cross-validation technique (Computed $F_{\text {roll }}$ ) on (a) hard smooth and (b) carpet surfaces. (Solid line is identity line.)

results make it possible to advise home architects not to use carpet, both to increase the mobility of MWC users and to decrease muscle and joint strain.

For every type of wheel, the RP values were found to be significantly higher on carpet than on the hard smooth surface, which explains the differences noted in the decelerations and rolling resistances. This result is explained by floor deformations for carpet that did not occur for the hard smooth surface. As a consequence, the use of a carpet surface should decrease the mobility of MWC users and increase the risk of musculoskeletal disorders.

The high RP of standard casters reflects the low rolling properties of their materials, which require improve- ments to decrease the rolling resistance. Conversely, roller casters showed materials with high rolling properties. Unexpectedly, although the soft casters were the most deformable, their RP was not the highest. This result could be explained by the high elastic properties of these caster materials. Hence, the RP value depended not only on the wheel softness but also on the elastic properties of their materials. The effect of the tire pressure, previously demonstrated $[2,4]$, was not found in our results. However, the inclusion of six cambered wheels - which showed slightly higher RP values than noncambered wheels - in the group of tires inflated to 87.0 psi could

Table 3.

Mean \pm standard deviation rolling resistance parameters (RPs) of front and rear wheels according to wheel type.

\begin{tabular}{llccc}
\hline Type & $\mathbf{R P}\left(\times \mathbf{1 0}^{-\mathbf{3}} \mathbf{~}\right)$ & Hard Smooth & Carpet & $\boldsymbol{p}$-Value \\
\hline Front & Soft Caster & $0.83 \pm 0.34$ & $2.67 \pm 0.52$ & 0.006 \\
& Standard Caster & $1.94 \pm 0.85$ & $3.54 \pm 0.68$ & $<0.001$ \\
& Roller Caster & $0.36 \pm 0.14$ & $1.84 \pm 0.54$ & 0.01 \\
& & $p<0.001$ & $p<0.001$ & \\
Rear & Solid Tire & $4.93 \pm 1.83$ & $6.92 \pm 1.60$ & $<0.001$ \\
& Pneumatic Tire & $1.28 \pm 0.73$ & $4.84 \pm 1.23$ & $p<0.001$ \\
& $p<0.001$ & & \\
\hline \hline
\end{tabular}


partially explain the highest RP found for this group. In addition, the pneumatics inflated to 43.5 and $65.0 \mathrm{psi}$ exhibited larger widths than the pneumatics inflated to $87.0 \mathrm{psi}$, which could also partially explain the fact that the highest RP was obtained for the latter group. Indeed, under the same load and pressure conditions, the contact area would be the same for any tire width. Hence, the main axis of the ellipse area drops with an increase in tire width, which decreases the RP. Therefore, the expected decrease in the RP with tire pressure might have been impaired by the negative effects of both the camber and thinness of the pneumatics inflated to 87.0 psi. In addition, these results clarify the low effect of the tire pressure from 43.5 to 87.0 psi. However, keep in mind that MWC users generally do not maintain tire pressure, which could lead to a significant increase in the rolling resistance when tire pressure falls below 43.5 psi. Thus, further experiments carried out with different pressures on the same tires would allow both verification and quantification of the influence of the tire pressure on RP. Finally, the solid tires exhibited significantly higher RP values than the pneumatics. Considering that the solid and pneumatic rear wheels had similar radii, the fact that the former exhibited a higher RF than the latter is consistent with the previous results [5-6,27]. Thus, even if solid tires do not need to be maintained, improvements in their materials are required to reach the rolling properties of pneumatic tires. Thus, solid tires would decrease the mobility of MWC users and could lead to potential risks of muscle and joint disorders.

Beyond wheel comparisons, this knowledge of RP values makes determining the wheel radii that provide the same RF possible. For that, the ratio between the radii of the wheels must be the inverse of this between RP. As an example, the standard casters would need radii 5.4 times higher than those of roller casters to provide the same RF on a hard smooth surface. In the same way, pneumatic rear wheels would need radii 3.6-, 1.5-, and 0.7 -fold those of roller, soft, and standard casters, respectively, to provide the same RF on a hard smooth surface. Considering that the radii of the front casters generally range from 0.03 to $0.10 \mathrm{~m}$, the $\mathrm{RF}$ values of the rear wheels are lower than those of the front casters. Consequently, both clinicians and MWC users should probably not focus on the choice of rear wheel pneumatics but rather on the front casters.

The method presented in this article would help clinicians to make trade-offs, both when choosing MWCs and when making adjustments, based on a quantitative evaluation of the subject-specific MWC rolling resistance. The method includes a mechanical model (Equation (4)) and input data (Table 3), which just require measurements of the wheel radii and load applied to the front and rear wheels when a user sits in the MWC. Furthermore, the model can be applied to any mechanical system equipped with front and rear wheels (e.g., wheelchairs, strollers, or medical beds) and only needs a few inputs: wheel radii, masses applied on front and on rear wheels, and specific RP. The input data (RP summarized in Table 3) makes reducing the measurements possible, thereby making the method usable in a clinical environment. The validity of the method was investigated with a crossvalidation technique and gave acceptable results when predicting MWC rolling resistances on both tested surfaces. Further experiments performed on other surfaces (indoor and/or outdoor) would be useful to assess the specific MWC rolling resistance on the surface on which the user mainly rolls. However, the use of different types of front and rear wheels will be required on each surface.

Finally, clinicians could use the method to adjust the MWC for users with regard to subject-specific MWC rolling resistance. The method could also be used by engineers to enhance MWCs and by architects to improve the accessibility of private and public buildings for MWC users.

\section{CONCLUSIONS}

This study presented a simple and convenient method for the assessment of subject-specific MWC rolling resistance during propulsion on hard smooth and carpet surfaces. Rolling resistance properties were quantified from experiments and used as input data in the model. Thus, the method could be easily incorporated into a clinical routine.

The experiments allowed us to confirm various considerations, such as the higher rolling resistance of (1) solid tires on the rear wheels compared with pneumatic tires, (2) front casters compared with rear wheels, and (3) carpet compared with a hard smooth surface. Thus, carpet and solid tires should be avoided to improve both the mobility and accessibility of MWC users and decrease the potential risk of upper-limb disorders. Although these recommendations already exist, this study provided 
quantified data comparing several parameters like surfaces and wheel types and sizes.

Assessments of MWC rolling resistances from the method showed acceptable accuracy on both tested surfaces. In addition, this method could easily be implemented in a calculus sheet that would help clinicians to choose a MWC, its wheels, and its adjustments based on the subject and environment. It should also help MWC manufacturers during the development of their products and should help architects enhance the accessibility of buildings. Finally, daily use of this method in various fields should decrease the rolling resistance sustained by MWC users in their daily life, which would improve their mobility and contribute to the prevention of muscle and joint disorders.

In the future, it would be interesting to enlarge this study to other common indoor or outdoor floors such as asphalt or clay ground. The modeling of the tire pressure effect on the rolling resistance could also be interesting, particularly to quantify the rolling resistance for low pressures, which are often used by MWC users.

\section{ACKNOWLEDGMENTS}

\author{
Author Contributions: \\ Study concept and design: C. Sauret, J. Bascou, N. de Saint Rémy, \\ H. Pillet, P. Vaslin. \\ Acquisition of data: C. Sauret, J. Bascou, N. de Saint Rémy. \\ Analysis and interpretation of data: C. Sauret, J. Bascou. \\ Drafting of manuscript: C. Sauret, J. Bascou. \\ Statistical analysis: C. Sauret, J. Bascou. \\ Critical revision of manuscript for important intellectual content: \\ H. Pillet, P. Vaslin, F. Lavaste. \\ Obtained funding: F. Lavaste. \\ Study supervision: F. Lavaste.
}

Financial Disclosures: The authors have declared that no competing interests exist.

Funding/Support: This material was based on work supported by the SACR-FRM project, French National Research Agency (ANR-06TecSan-020) and the Centre d'Etudes et de Recherche sur l'Appareillage des Handicapés (loaned all MWCs required to fulfill this work).

\section{REFERENCES}

1. Hofstad M, Patterson PE. Modelling the propulsion characteristics of a standard wheelchair. J Rehabil Res Dev. 1994;31(2):129-37. [PMID: 7965869]
2. Kauzlarich JJ, Thacker JG. Wheelchair tire rolling resistance and fatigue. J Rehabil Res Dev. 1985;22(3):25-41. [PMID: 3835263]

3. Van der Woude LH, Veeger HE, Dallmeijer AJ, Janssen TW, Rozendaal LA. Biomechanics and physiology in active manual wheelchair propulsion. Med Eng Phys. 2001;23(10):713-33. [PMID: 11801413]

4. Van der Woude LH, De Groot S, Janssen TW. Manual wheelchairs: Research and innovation in sports and daily life. Science Sports. 2006;21(4):226-35. http://dx.doi.org/10.1016/i.scispo.2006.06.006

5. Gordon J, Kauzlarich JJ, Thacker JG. Tests of two new polyurethane foam wheelchair tires. J Rehabil Res Dev. 1989;26(1):33-46. [PMID: 2918486]

6. Kwarciak AM, Yarossi M, Ramanujam A, Dyson-Hudson TA, Sisto SA. Evaluation of wheelchair tire rolling resistance using dynamometer-based coast-down tests. J Rehabil Res Dev. 2009;46(7):931-38. [PMID: 20104415]

7. Veeger D, Van der Woude LH, Rozendal RH. The effect of rear wheel camber in manual wheelchair propulsion. J Rehabil Res Dev. 1989;26(2):37-46. [PMID: 2724151]

8. Faupin A, Campillo P, Weissland T, Gorce P, Thevenon A. The effects of rear-wheel camber on the mechanical parameters produced during the wheelchair sprinting of handibasketball athletes. J Rehabil Res Dev. 2004;41(3B):421-28. [PMID: 15543460]

9. Cooper RA. A systems approach to the modeling of racing wheelchair propulsion. J Rehabil Res Dev. 1990;27(2): 151-62. [PMID: 2366199]

10. Lemaire ED, Lamontagne M, Barclay HW, John T, Martel G. A technique for the determination of center of gravity and rolling resistance for tilt-seat wheelchair. J Rehabil Res Dev. 1991;28(3):51-58. [PMID: 1880750]

11. Sauret C, De Saint Rémy N, Vaslin P, Cid M, Dabonneville M, Kauffmann P. Theoretical comparison of the resultant braking force applied on a manual wheelchair within a propulsion cycle on the field and on laboratory ergometers. Model Meas Control C. 2006;67:43-52.

12. Sauret C, Vaslin P, Dabonneville M, Cid M. Drag force mechanical power during an actual propulsion cycle on a manual wheelchair. IRBM. 2009;30(1):3-9. http://dx.doi.org/10.1016/j.jrbm.2008.10.002

13. Sauret $C$. Cinétique et énergétique de la propulsion en fauteuil roulant manuel [Kinetics and energetics of manual wheelchair propulsion] [dissertation]. Clermont-Ferrand (France): Université Blaise Pascal; 2010. 404 p. French.

14. De Saint Rémy N, Vaslin P, Dabonneville M, Martel L, Gavand A. Dynamique de la locomotion en fauteuil roulant manuel: Influences de la masse totale et de sa répartition antéropostérieure sur la résultante des forces de freinage. [Dynamics of manual wheelchair locomotion: Influences of the level and the fore-and-aft distribution of the total 
mass on the resultant braking force]. Science Sports. 2003;18(3):141-49. French. http://dx.doi.org/10.1016/S0765-1597(03)00076-5

15. De Saint Rémy N. Modélisation et détermination des paramètres biomécaniques de la locomotion en fauteuil roulant manuel [Modeling and computation of biomechanical parameters of manual wheelchair locomotion] [dissertation]. Clermont-Ferrand (France): Université Blaise Pascal; 2005. 234 p. French.

16. Brubaker CE, McLaurin CA, McClay IS. Effects of side slope on wheelchair performance. J Rehabil Res Dev. 1986;23(2):55-58. [PMID: 3723426]

17. Coutts KD. Dynamic characteristics of a sport wheelchair. J Rehabil Res Dev. 1991;28(3):45-50. [PMID: 1880749] http://dx.doi.org/10.1682/JRRD.1991.07.0045

18. Coutts KD. Drag and sprint performance of wheelchair basketball players. J Rehabil Res Dev. 1994;31(2):138-43. [PMID: 7965870]

19. Vinet A, Bernard PL, Ducomps C, Selchow O, Le Gallais D, Micallef JP. A field deceleration test to assess total wheelchair resistance. Int J Rehabil Res. 1998;21(4):397-401. [PMID: 9926355] http://dx.doi.org/10.1097/00004356-199812000-00007

20. Hoffman MD, Millet GY, Hoch AZ, Candau RB. Assessment of wheelchair drag resistance using a coasting deceleration technique. Am J Phys Med Rehabil. 2003;82(11): 880-89. [PMID: 14566157] http://dx.doi.org/10.1097/01.PHM.0000091980.91666.58

21. Bascou J, Sauret C, Pillet H, Lavaste F, Vaslin P. Error estimations of wheelchair deceleration tests using a 3D accelerometer. Comp Meth Biomech Biomed Eng. 2010; 13(Suppl 1):21-22. http://dx.doi.org/10.1080/10255842.2010.490091

22. Sauret C, Bascou J, Pillet H, Lavaste F, Vaslin P. Repeatability of wheelchair deceleration tests using a 3-D accelerometer. Comp Meth Biomech Biomed Eng. 2010;13(Suppl 1): 137-38. http://dx.doi.org/10.1080/10255842.2010.495874

23. Vaslin P, Dabonneville M. Use of a 3D accelerometer for kinetic analysis of wheelchair propulsion. Proceedings of the 12th Conference of the European Society of Biomechanics; 2000 Aug 28-33; Dublin, Ireland. Dublin (Ireland): Royal Academy of Medicine in Ireland; 2000.

24. Frank TG, Abel EW. Measurement of the turning, rolling and obstacle resistance of wheelchair castor wheels. J Biomed Eng. 1989;11(6):462-66. [PMID: 2811344] http://dx.doi.org/10.1016/0141-5425(89)90040-X

25. Chua JJ, Fuss FK, Subic A. Rolling friction of a rugby wheelchair. Procedia Engineering. 2010;2(2):3071-76. http://dx.doi.org/10.1016/j.proeng.2010.04.113

26. Koontz AM, Cooper RA, Boninger ML, Yang Y, Impink BG, Van der Woude LH. A kinetic analysis of manual wheelchair propulsion during start-up on select indoor and outdoor surfaces. J Rehabil Res Dev. 2005;42(4):447-58. [PMID: 16320141] http://dx.doi.org/10.1682/JRRD.2004.08.0106

27. Sawatzky BJ, Kim WO, Denison I. The ergonomics of different tyres and tyre pressure during wheelchair propulsion. Ergonomics. 2004;47(14):1475-83. [PMID: 15697064] http://dx.doi.org/10.1080/00140130412331290862

Submitted for publication March 18, 2011. Accepted in revised form July 26, 2011.

This article and any supplementary material should be cited as follows:

Sauret C, Bascou J, de Saint Rémy N, Pillet H, Vaslin P, Lavaste F. Assessment of field rolling resistance of manual wheelchairs. J Rehabil Res Dev. 2012;49(1):63-74. http://dx.doi.org/10.1682/JRRD.2011.03.0050

ResearcherID: Christophe Sauret, PhD: H-2410-2011; Joseph Bascou, MS: H-2414-2011.

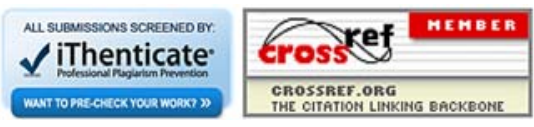

